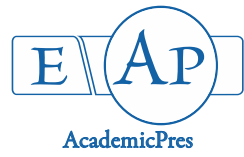

\title{
Impact of Hydrogen Peroxide on the Secondary Metabolites, Enzyme Activities and Photosynthetic Pigment Accumulation of Vigna unguiculata L. (Walp)
}

\author{
Ezekiel Dare OLOWOLAJU*
}

Obafemi Awolowo University, Faculty of Science, Department of Botany, Ile-Ife, Nigeria; barenleezekiel@yahoo.com (*corresponding author)

\begin{abstract}
The effects of exogenous application of hydrogen peroxide on the secondary metabolites, enzyme activities and photosynthetic pigment accumulation of Vigna unguiculata was investigated. The hereby study was carried out under a screen house to minimize extraneous factors. The experiment was laid down in completely randomized design (CRD) with eight replicates. After two weeks of sowing when the seedlings become fully established, the sample pots were divided into two regimes. The first regimes were supplied daily with $500 \mathrm{~mL}$ of $0.1 \mathrm{mM}$ of hydrogen peroxide and the second regime was watered daily with tap water. After fifth week of sowing, the leaves of Vigna unguiculata from each regime were randomly selected and harvested. Secondary metabolites, enzyme assay and photosynthetic pigment screening was carried out on the harvested leaves. The impact of hydrogen peroxide on the parameters studied was done using one way analysis of variance. Mean values were separated using Fisher's LSD at $p \leq 0.05$. The results showed that hydrogen peroxide strongly increased the accumulation of secondary metabolites such as flavonoids, glycosides, saponins, carbohydrates and alkaloids. It also induced $\alpha$ amylase and lipase activities than the control plants and promotes the accumulation and biosynthesis of chlorophylls and carotenoids. In conclusion, hydrogen peroxide could be used as potential molecule to improve some secondary metabolites (flavonoids, glycosides, saponins, carbohydrates and alkaloids), $\alpha$-amylase and lipase activities and photosynthetic pigments.
\end{abstract}

Keywords: chlorophyll; enzyme; hydrogen peroxide; metabolites; pigments

\section{Introduction}

Hydrogen peroxide $\left(\mathrm{H}_{2} \mathrm{O}_{2}\right)$ and other reacting oxygen species such as the superoxide anion radical $\left(\mathrm{O}^{-}\right)$, hydroxyl radical $\left(\mathrm{HO}^{-}\right)$, perhydroxyl radical $\left(\mathrm{HO}_{2}^{-}\right)$, and singlet oxygen $\left(\mathrm{O}_{2}{ }^{-}\right)$(Bartosz, 1997; Dat et al., 2000; Halliwell, 2006) generally, are fundamental fact of life in an aerobic environment (Moller, 2001). Hydrogen peroxide being the most stable reacting oxygen species, it is an important cellular component with various functions in the development, metabolism and homeostasis of aerobic organisms (Bienert et al., 2006) and regulate basic internal and external physiological processes such as photosynthesis, respiration, cell elongation and division (Barba-Espin et al., 2010). In plants $\mathrm{H}_{2} \mathrm{O}_{2}$ is generated via superoxide, presumably in a non-controlled manner, during electron transport processes such as photosynthesis and mitochondrial respiration (Neill et al., 2002). Slesak et al.
(2007) suggested that $\mathrm{H}_{2} \mathrm{O}_{2}$ plays a crucial role as a signaling molecule in various physiological processes such as photosynthesis, respiration, translocation and transpiration. When catalyzed in water, $\mathrm{H}_{2} \mathrm{O}_{2}$ may generate a wide variety of free radicals and other reactive species that are capable of transforming or decomposing organic chemicals (Petri et al., 2003). Hydrogen peroxide $\left(\mathrm{H}_{2} \mathrm{O}_{2}\right)$ is therefore a strong and viable oxidant that long has been applied in agriculture, industries and water treatment processes.

Hydrogen peroxide has been shown to serve a dual role in plants at low and high concentrations. At low concentrations, it is said to acts as a messenger molecule involved in acclamatory signaling, triggering tolerance against various abiotic stresses, and at high concentrations it orchestrates programmed cell death (Vandenabeele et al., 2003), act as a signal in the induction of gene expression of the enzymes catalase (Polidoros and Scandalios, 1999), Changes in hydrogen peroxide homeostasis and also induces synthesis of heat shock proteins and activates the mitogenactivated protein kinase cascade (Van Breusegem et al., 2001). 
392

Understanding the role of $\mathrm{H}_{2} \mathrm{O}_{2}$ in regulating some important processes in plants maybe a driver and pivotal for the production and synthesis for some substrates which are required for plant growth and development. The aim of this study was to evaluate the effects of hydrogen peroxide on the on the secondary metabolites, enzyme activities and photosynthetic pigment accumulation of Vigna unguiculata.

\section{Materials and Methods}

\section{Raising of seedlings}

Seeds of Vigna unguiculata L. (Walp) of variety IT99K573-3-1 was used in this study and was collected from the Department of Crop Production and Protection, Faculty of Agriculture, Obafemi Awolowo University, Ile Ife, Nigeria. The seedlings were raised under a screen house to minimize extraneous factors. 32 pots were obtained (of $9 \mathrm{~cm}$ in diameter and $7.5 \mathrm{~cm}$ in height). These pots were filled with $10 \mathrm{~kg}$ of collected soil. Holes of about $3 \mathrm{~mm}$ were bored at the bottom of the bowls. This is to allow for proper drainage and prevent water logging during the course of the experiment. The seeds of this variety were then being sown at a depth of about $3 \mathrm{~mm}$ below the soil. These seeds were sown at the rate of three seeds per pot. The pots were then supplied with $500 \mathrm{~mL}$ of tap water daily until the seedlings become fully established. The experiment was laid down in completely randomized design (CRD) with eight replicates. After two weeks of sowing when the seedlings become fully established, the sample pots were divided into two regimes. The first regimes were supplied daily with $500 \mathrm{~mL}$ of 0.1 $\mathrm{Mm}$ of hydrogen peroxide and the second regime were watered daily with tap water. After fifth week of sowing, the leaves of Vigna unguiculata from each regime were randomly selected and harvested. Secondary metabolites, enzyme assay and photosynthetic pigment screening was carried out on the harvested leaves.

\section{Screening of secondary metabolites}

Qualitative screening of secondary metabolites was carried out to ascertain the presence of the different phytochemicals according to the methods of Sofowora (1982) and Ghani (1998).

\section{Test for tannins}

Tannin was determined by the Folin-Denis colorimetric method. About $0.5 \mathrm{~g}$ of the extracts of each plant were boiled in $20 \mathrm{~mL}$ of water in a test tube and then filtered. A few drops of $0.1 \%$ ferric chloride were added. A brownish green or a blue-black coloration indicated the presence of tannins.

\section{Test for saponins}

Two (2) mg of the extracts of each plant is boiled together with $20 \mathrm{~mL}$ of distilled water in a water bath, vigorously shaken and noted for froth. The appearance and persistence of frothing before and after warming indicated the presence of saponins.

Test for flavonoids

Five (5) $\mathrm{mL}$ of dilute ammonia solution was added to the ethanolic extract of each plant sample in a test tube, followed by addition of concentrated $\mathrm{H}_{2} \mathrm{SO}_{4}$. A yellow coloration was observed and disappeared on standing. This indicated the presence of flavonoids.

\section{Test for phenol}

Five hundred (500) $\mathrm{mg}$ of the extract was dissolved in 5 $\mathrm{mL}$ of distilled water. To this, few drops of neutral ferric chloride solution was added. A dark green color indicated the presence of phenolic compounds.

\section{Test for alkaloids}

Five (5) $\mathrm{mL}$ solution of the extract and $2 \mathrm{~mL}$ of dilute hydrochloric acid were taken in a test tube. Then $1 \mathrm{~mL}$ of Dragendroffs reagent was added to this acidic medium. Orange or red precipitate was formed and that was indicated as the presence of alkaloids.

\section{Test for steroids}

Two (2) $\mathrm{mL}$ of acetic anhydride were added to $0.5 \mathrm{~g}$ ethanolic extract of each sample with $2 \mathrm{~mL} \mathrm{H}_{2} \mathrm{SO}_{4}$. The change of color from violet to blue or green in some samples indicated the presence of steroids.

\section{Test for soluble sugars}

About $5 \mathrm{~g}$ each of the dried samples was introduced into a test tube and equal amount of Fehling's solution A and B were added. The mixture was boiled over a burner. Observation of colour was made. The colour changed from deep blue to brick red.

\section{Test for glycosides}

One milliliter of extract will be added to one milliliter of water and then aqueous sodium hydroxide was added. Formation of a yellow color indicated the presence of glycosides.

\section{Test for terpenoids}

Two millilitres of chloroform and one millilitre of concentrated tetraoxosulphate (VI) acid will be added to one milligram of extract. The formation of reddish brown colour indicated the presence of terpenoid.

\section{Determination of chlorophylls and carotenoids}

Before the application of salts, during stress period and during recovery period, $8 \mathrm{~g}$ of leaves from each plant will be harvested; the leaves will be grinded with mortar and pestle. A pinch of sodium bicarbonate will be added to the mixture to prevent the degradation of chlorophyll. $16 \mathrm{ml}$ of $80 \%$ acetone will be added. The blended materials will then filter through a Whatman's No. 1 filter paper (Coombs et al., 1990). The absorbance of the samples will be determined on a digital spectrophotometer at wavelengths of $470 \mathrm{~nm}, 646$ $\mathrm{nm}$ and $663 \mathrm{~nm}$. A Beer-Lambert equation will be used to determine the concentrations of Chlorophyll a and Chlorophyll $b$ and the carotenoid in the leaf extract as follows:

Chlorophyll a $(\mu \mathrm{g} / \mathrm{ml})=12.21 \mathrm{~A} 663-2.81 \mathrm{~A} 646$

Chlorophyll b $(\mu \mathrm{g} / \mathrm{ml})=20.13 \mathrm{~A} 646-5.03 \mathrm{~A} 663$

Carotenoids $(\mu \mathrm{g} / \mathrm{ml})=(1000 \mathrm{~A} 470-3.27[\mathrm{Chl} \mathrm{a}]-$ $104[\mathrm{Chl} \mathrm{b}]) / 227$ 
Total chlorophyll $(\mu \mathrm{M})=7.93 \mathrm{~A} 663+19.53 \mathrm{~A} 646$

In the carotenoid equation, '[chl a]' and '[chl b]' refer to the calculated concentration of chl $\mathrm{a}$ and chl $\mathrm{b}$ from the previous equations. A663 represent the absorbance at wavelength $663 \mathrm{~nm}$ while A646 represents the absorbance at wavelength $646 \mathrm{~nm}$.

\section{Enzyme assays}

Assays for antioxidative enzymes were conducted according to methods reported previously (Azevedoet al., 2005). All extraction procedures were carried out at $4^{\circ} \mathrm{C}$. The plants samples, weighting about $0.245 \mathrm{~g}$, will be homogenized with $5.4 \mathrm{~mL}$ of tris ( $\mathrm{pH} 7.8$ ), followed by centrifugation of $20000 \mathrm{~g}$ for $20 \mathrm{~min}$. The supernatants were used for determination of enzyme activity.

\section{a-Amylase assay}

The activity of amylase was measured by using the method based on Bernfield (1955). The reaction mixture contains $\mathrm{pH} 6.9$ and $0.5 \mathrm{~mL}$ of homogenates and was incubated at room temperature for 3 minutes. Further added was $1.0 \mathrm{~mL}$ of 3,5-dinitosalicyclic acid (DNSA) solution. The reaction mixture was boiled for $5 \mathrm{~min}$, allowed to cool and followed by the addition of $20 \mathrm{~mL}$ of distilled water. Absorbance was read at $540 \mathrm{~nm}$ against a blank. One unit of enzyme activity is defined as the amount of enzyme that will release $1 \mu \mathrm{mol}$ of glucose of reducing sugar in 1 minute under assay conditions. The amount of maltose was obtained from standard calibration curve using glucose standard solution.

Enzyme activity was calculated using the below formula;

Activity $=$ OD/Slope $\times$ V.E x 10 minutes

Where $\mathrm{OD}=$ Optical density at $540 \mathrm{~nm}$; V.E = Volume of enzyme.

\section{Lipase assay}

Lipase activity was assay spectrochemically using pnitrophenyllaurate (P-NPL) according to the method of Rouhi et al. (2012) with slight modification. The emulsion was prepared by first by dissolving $0.001 \mathrm{~g}$ of pNPL in $1 \mathrm{~mL}$ of isopropanol and then mixing it with $9 \mathrm{~mL}$ of $0.05 \mathrm{M}$ tris$\mathrm{HCl}(\mathrm{pH} 7.5)$ containing $50 \mu \mathrm{L}$ trition X-100 and $0.01 \mathrm{~g}$ gum Arabic. A total of $700 \mu \mathrm{L}$ of the freshly prepared substrate solution was mixed with $300 \mu \mathrm{L}$ of the appropriately diluted enzyme solution. The liberated pNPL was monitored by the change in the absorbance at $410 \mathrm{~nm}$ at an interval of 15 seconds over 3 minutes period using spectrophotometer. One unit $(1 \mu)$ of the enzyme activity is defined as the amount of enzyme that released $1 \mu \mathrm{mol}$ of of p-nitrophenol from PNPL in one minute $\left(\varepsilon=15600 \mathrm{~m}^{-1}\right.$ $\mathrm{cm}^{-1}$ ) under the assay conditions.

Enzyme activity was calculated using the below formula; Lipase activity $=\underline{A b s 410 \mathrm{~nm} / \min \times \mathrm{V}}$

$$
\varepsilon \times C
$$

Where $\mathrm{Abs} 410 \mathrm{~nm} / \mathrm{min}=$ change in absorbance at 410 $\mathrm{nm} ; \mathrm{V}=$ total volume of the assay mixture; $\mathrm{C}=$ volume of the assay mixture; $\varepsilon=$ extinction coefficient $\left(15,600 \mathrm{~m}^{-1}\right.$ $\mathrm{cm}^{-1}$ ).

\section{Results}

Exogenous application of hydrogen peroxide on the phytochemical constituents of Vigna unguiculata

The effect of exogenous application of hydrogen peroxide on the secondary metabolites of Vigna unguiculata is shown on Table 1. Glycosides, resins, saponins, flavonoids, carbohydrates and alkaloids were found to be present in the control plants. Flavonoids, glycosides, saponins, carbohydrates and alkaloids were found to be present in the Vigna unguiculata treated with hydrogen peroxide. Flavonoids, glycosides, saponins, carbohydrates and alkaloids were strongly present in Vigna unguiculata treated with hydrogen peroxide, while glycosides, flavonoids, carbohydrates and alkaloids were weakly present and resins and saponins were moderately present in the control plants.

Exogenous application of magnetized water on some enzyme activities in the leaf of Vigna unguiculata

Exogenous application of hydrogen peroxide on the hydrolytic enzyme activities in the leaf of Vigna unguiculata is shown on Table 2. $\alpha$-Amylase activity in the leaf of Vigna unguiculata treated with hydrogen peroxide was higher than the control plants. Also, lipase activity in the leaf of cowpea treated with hydrogen peroxide was higher than the control plants. There was significant difference in the $\alpha$-Amylase of the control plant and with those treated with hydrogen peroxide at $\mathrm{p} \leq 0.05$.

Table 1. Exogenous application of hydrogen peroxide on the of Vigna unguiculata

\begin{tabular}{ccc}
\hline Secondary metabolites & Treatments with hydrogen peroxide & Control \\
\hline Tannins & - & +++ \\
Glycosides & - & +++ \\
Resins & - & ++ \\
Saponins & +++ \\
Phlobatannins & - \\
Flavonoids & - & + \\
Sterols & +++ \\
Phenols & +++ \\
Carbohydrates & - \\
Alkaloids & + \\
Terpenoids & + \\
\hline$-=$ Negative test (Absence of precipitation); $+=$ Weak positive (A slight opacity/precipitation); $++=$ Positive test (Reactive product (Precipitation); $+++=$ Test strongly \\
positive
\end{tabular}


Table 2. Exogenous application of hydrogen peroxide on some enzyme activities in the leaf of cowpea

\begin{tabular}{ccc}
\hline Treatments & $\alpha$-Amylase & Lipase \\
\hline Hydrogen peroxide & $12.88^{\mathrm{a}}$ & $0.43^{\mathrm{a}}$ \\
Control & $37.32^{\mathrm{b}}$ & $0.18^{\mathrm{b}}$ \\
LSD & 12.37 & 0.02 \\
CV\% & 11.46 & 5.86 \\
\hline Means with the sameletter along the same column are not significantly different 2 t $\mathrm{p} \leq 0.05$. LSD $=$ Least Significantly Different: CV=Coefficient of Variance
\end{tabular}

Table 3. Exogenous application of hydrogen peroxide on the photosynthetic pigment accumulation of cowpea

\begin{tabular}{|c|c|c|c|c|}
\hline Treatments & Chlorophyll a & Chlorophll b & Total chlorophyll & Carotenoid \\
\hline H. peroxide & $15.04^{a}$ & $14.09^{\mathrm{a}}$ & $26.02^{\mathrm{a}}$ & $2055.72^{\mathrm{a}}$ \\
\hline Control & $9.13^{\mathrm{b}}$ & $6.11 \mathrm{~b}$ & $23.62^{b}$ & $1748.52^{b}$ \\
\hline LSD & 0.00 & 0.00 & 0.00 & $439 \mathrm{E}-8$ \\
\hline CV\% & 0.00 & 0.00 & 0.00 & $1.79 \mathrm{E}-7$ \\
\hline
\end{tabular}

Exogenous application of hydrogen peroxide on the photosynthetic pigment accumulation of Vigna unguiculata

Table 3 showed the effect of magnetized water on the photosynthetic pigment accumulation of Vigna unguiculata. Chlorophyll a, chlorophyll b, total chlorophyll and carotenoid accumulation of Vigna unguiculata treated with hydrogen peroxide were higher than the control plants. Chlorophyll a, chlorophyll b, total chlorophyll and carotenoid accumulation of Vigna unguiculata treated with magnetized water were significantly different from the control plant at $\mathrm{p} \leq 0.05$.

\section{Discussion}

The positive test for the presence of glycosides, resins, saponins, flavonoids, carbohydrates and alkaloids in the control indicated that these secondary metabolites were active in the study plants. The strongly presence of flavonoids, glycosides, saponins, carbohydrates and alkaloids indicated that hydrogen peroxide enhanced the accumulation of these secondary metabolites and likely to increased their activities when produced endogenously. The absence of resins in the plants treated with hydrogen peroxide but present in the control plants showed that hydrogen peroxide inhibit the synthesis of resins. Secondary metabolites are the useful natural products that are synthesized through secondary metabolism in the plants.

Plant treated with hydrogen peroxide and the control showed a significant difference in $\alpha$-amylase and lipase activity in the leaf of study plants. The significant difference in the activities of these enzymes showed that hydrogen peroxide promotes the activities of these enzymes. This is in line with the study of Dolatabadian and Modarres (2008) that seed priming and exogenous application of hydrogen peroxide increased catalase activity and lipid peroxidation in safflower and sunflower. $\alpha$-amylase and lipase are important enzymes in seed germination, regulation of the antioxidant system and starch and lipid metabolism.

Chlorophyll a, Chlorophyll b, total Chlorophyll and carotenoid accumulation were all enhanced in the study plants treated with hydrogen peroxide than the control. This showed that hydrogen peroxide played a significant role in the biosynthesis of chlorophylls and carotenoids.

\section{Conclusions}

From the result obtained it can be inferred that hydrogen peroxide induced the accumulation of secondary metabolites such as flavonoids, glycosides, saponins, carbohydrates and alkaloids. It also stimulates $\alpha$-amylase and lipase activity and enhanced the accumulation and biosynthesis of chlorophylls and carotenoids. This hereby study suggest that hydrogen peroxide could be used as potential molecules to improve some secondary metabolites (flavonoids, glycosides, saponins, carbohydrates and alkaloids), $\alpha$-amylase and lipase activity and photosynthetic pigments.

\section{Conflict of Interest}

The authors declare that there are no conflicts of interest related to this article.

\section{References}

Azeved AD, Prisco JT, Enéas-Filho J, Medeiros JR, Gomes-Filho E (2005). Hydrogen peroxide pre-treatment induces salt-stress acclimation in maize plants. Journal of Plant Physiology 162(10):1114-1122.

Barba-Espin GP, Diaz-Vivancos MJ, Clemente-Moreno A, Albacete FL (2010). Interaction between hydrogen peroxide and plant hormones during germination and the early growth of pea seedlings. Plant, Cell \& Environment 33(6):981-994.

Bartosz G (1997) Oxidative stress in plants. Acta Physiologiae Plantarum 19(1):47-64.

Bienert GP, Schjoerring JK, Jahn TP (2006). Membrane transport of hydrogen peroxide. Biochimica et Biophysica Acta 1758(8):994-1003.

Comb JH, Long SI, Scurlock J (1990). Techniques in bioproductivity and photosynthesis. $1^{\text {st }}$ Edn, Pergamon Press, Oxford, New York pp 225228

Dat J, Vandenabeele S, Vranová E, Van Montagu M, Inzé D, Breusegem F (2000). Dual action of the reactive oxygen species during plant stress responses. Cell Molecular and Life Science 57:779-795.

Ghani A (1998). Medicinal plants of Bangladesh, 1st ed. Dhaka Asiatic Societypp 11-41. 
Halliwell B (2006). Reactive species and antioxidants. Redox biology is a fundamental theme of aerobic life. Plant Physiology 141(2):312-322.

Møller IM (2001). Plant mitochondria and oxidative stress: electron transport, NADPH turnover, and metabolismof reactive oxygen species. Annual Review of Plant Biology 52(1):561-591.

Neill S, Desikan R, Hancock J (2002). Hydrogen peroxide signalling. Current Opinion in Plant Biology 5(5):388-395.

Petri BG, Watts RJ, Teel AL, HulingSG, Brown RA (2003). Fundamentals of ISCO using hydrogen peroxide. In: Siegrist RL, Crimi M, Simpkin TJ (Eds). In Situ Chemical Oxidation for Groundwater Remediation. Springer,New York, USA.

Polidoros A, Scandalios J (1999). Role of hydrogen peroxide and different classes of antioxidants in the regulation of catalase and glutathione-Stransferase gene expression in maize (Zea mays L.). Physiologia Plantarum106(1):112-120.

Rouhi HR, Aboutalebian MA, Moosavi SA, Karimi FA, Karimi F, Saman M, Samadi M (2012). Change in several antioxidant enzymes activity of Berseem clover (Trifolium alexandrinum $\mathrm{L}$ ) by priming. International Journal of Agricultural Science 2(3):237-243.
Slesak I, Libik M, Karpinska B, Karpinski S, Miszalski Z (2007). The role of hydrogen peroxide inregulation of plant metabolism and cellular signaling in response to environmental stresses. Acta Biochimica Polonica 54(1):39-50.

Sofowora A (1982). Medicinal plants and traditional medicine in Africa. John Wileyand Sons Ltd.

Van Breusegem F, Vranová E, Dat JF, Inzé D (2001). The role of active oxygen species in plant signal transduction. Plant Science 161(3):405414.

VandenabeeleS, Van Der Kelen K, Dat J, Gadjev I, Boonefaes T, MorsaS,... Van Breusegen F (2003). A comprehensive analysis of hydrogen peroxide-induced gene expression in tobacco. Proceeding of National Academy ofScience 100(26):16113-16118. 